\title{
Candida Myocarditis Without Valvulitis
}

WILLIAM G. FRANKLIN, MD

ARTHUR B. SIMON, MD

THOMAS M. SODEMAN, MD

Ann Arbor, Michigan
From the Departments of Internal Medicine (Section of Cardiology) and Pathology, University of Michigan Medical Center, Ann Arbor, Mich. Manuscript received May 19, 1975; revised manuscript received February 25, 1976, accepted March 24, 1976.

Address for reprints. Arthur B. Simon, MD, Heart Station, University Hospital, Ann Arbor, Mich. 48109
Thirty-one patients with systemic candidiasis at postmortem examination were found to have Candida involvement of the myocardium without valvulitis. Retrospective examination of their clinical course demonstrated that a new conduction disturbance was seen in 10, supraventricular arrhythmias in 5, QRS changes mimicking myocardial infarction in 3 , and pronounced $T$ wave changes in 13. Hypotension or shock was seen in 13 patients and could not be explained by coexistent bacteremia or blood loss in 8 . One patient died suddenly. Of 19 patients with systemic candidiasis without myocardial invasion, 4 had minor $T$ wave changes and one had a supraventricular arrhythmia. Candida invasion of the heart significantly complicates the clinical course in systemic candidiasis and should be suspected when a young person without preexistent heart disease has cultures positive for a Candida organism, a significant arrhythmia, conduction disturbance or other dramatic QRS change. The effect of therapy on Candida invasion of the heart is unknown.

Involvement of the heart by Candida organisms is being recognized more often than in the past. Although Candida endocarditis on prosthetic heart valves has received the most attention, ${ }^{1}$ direct involvement of the myocardium by Candida organisms without cardiac valve involvement has received little attention. The recognition of complete atrioventricular (A-V) block secondary to an abscess of the interventricular septum caused by Candida albicans reported from this institution ${ }^{2}$ prompted an analysis of the problem of Candida myocarditis without valvulitis.

\section{Methods}

Autopsy protocols for the years 1959 to 1974 at the University of Michigan Medical Center were examined for evidence of systemic candidiasis. From January 1959 through August 1972 only slide material was available for reexamination. From September 1972 thruugh December 1974, each case of systemic candidiasis was reviewed with particular attention to involvement of the myocardium. All cases were then assigned to either Group I, those with myocardial involvement, or Group II, those without such involvement, as determined microscopically. Cases in which myocardial involvement was coexistent or secondary to involvement of the valves were excluded. In verified cases the clinical course, serial clinical cardiac observations, electrocardiograms, chest roentgenograms and autopsy material were assessed. The pathologic material was reviewed with specific attention to (1) distribution of mycotic lesions in the heart, (2) extent of involvement of other organ systems, and (3) underlying illness.

\section{Results}

\section{Group I (Cases With Myocardial Involyement)}

Thirty-one patients with Candida involvement of the heart were identified. Twenty cases were noted in the 14 years from 1959 through 1972, and 11 additional cases in the 2 years from 1973 through 1974 (Table I). 
There were 20 male and 11 female subjects. The mean age at death was 35 years.

Associated cardiac disease: Three patients had cardiac disease before the terminal illness. One had hypertensive heart disease with left bundle branch block and an old myocardial infarction at autopsy. A second patient had rheumatic heart disease and had a mitral valve prosthesis 2 weeks before death. At postmortem examination the prosthesis and adjacent myocardium were free of infection but focal myocardial abscesses were noted. Blood cultures were positive for Candida, but the source of the infection was unknown. Neither patient had a new conduction disturbance or arrhythmia during the terminal illness. One other patient had Libman-Sacks involvement of the mitral valve at autopsy. Two patients were receiving digitalis and had mild $\mathrm{T}$ wave abnormalities consistent with use of this agent. No electrolyte or acid-base disorders coincided with the appearance of the electrocardiographic abnormalities.

Predisposing illness: Most patients had been chronically ill for several months before the terminal illness. More than half the patients spent part or all of the terminal illness in an acute care facility where continuous monitoring was carried out. Almost all had multiple indwelling intravenous catheters at the time of death. Antibiotic agents were being given to $27 \mathrm{pa}-$ tients and antineoplastic drugs to $9 ; 16$ were receiving

\section{TABLE I}

Age at Death, Underlying Condition and Organism Recovered

\begin{tabular}{|c|c|c|}
\hline & $\begin{array}{c}\text { Group I } \\
\text { (Myocarditis) } \\
\text { (no. }=31 \text { ) }\end{array}$ & $\begin{array}{c}\text { Group II } \\
\text { (Without } \\
\text { Myo- } \\
\text { carditis) } \\
\text { (no. = 19) }\end{array}$ \\
\hline \multicolumn{3}{|l|}{ Age at death $(\gamma r)$} \\
\hline$<1$ & 4 & 1 \\
\hline $1-21$ & 6 & 5 \\
\hline $22-65$ & 19 & 13 \\
\hline$>65$ & 2 & \\
\hline Mean & 35 & 39 \\
\hline \multicolumn{3}{|l|}{ Underlying condition } \\
\hline Blood dyscrasias & 10 & 9 \\
\hline Solid tissue neoplasm & 2 & \\
\hline Postabdominal operation & 6 & $i$ \\
\hline Post thoracotomy & 1 & \\
\hline Bodv burn & 2 & 4 \\
\hline \multicolumn{3}{|l|}{ Neonatal disease (respiratory distress } \\
\hline Mediastinitis & $\ldots$ & 1 \\
\hline Enterocolıtis & 1 & 2 \\
\hline Protein-losing enteropathy & 1 & \\
\hline Disseminated lupus erythematosus & 1 & 1 \\
\hline Hyperalimentation & & 1 \\
\hline Amyloidosis & 1 & . \\
\hline Multiple sclerosis & 1 & \\
\hline Cirrhosis & 1 & . \\
\hline Hemophilia & 1 & . \\
\hline \multicolumn{3}{|l|}{ Diabetes mellitus, renal transplanta- } \\
\hline tion & 1 & . \\
\hline \multicolumn{3}{|l|}{ Candida organism cultured (any site) } \\
\hline Candida albicans & 21 & 15 \\
\hline Candida tropicalis & 5 & \\
\hline Species not specified & 5 & 4 \\
\hline
\end{tabular}

corticosteroids; 11 had undergone a major operative procedure within 2 months of death; 6 had had a minor operative procedure (peritoneal dialysis, arterial shunt, skin graft, among others) within 1 month of death. Ten patients had blood dyscrasias such as leukemia or aplastic anemia; two had solid tissue neoplasm and two had body burns. Three infants had neonatal illnesses (enterocolitis, malabsorption syndrome) (Table I).

Severe hypotension or shock complicated the clinical course in 13, but in 5 no bacteremia was present. In six patients with shock, neither bacteremia nor blood loss was present at the time of shock. One patient died suddenly and unexpectedly. Other modes of death included renal and hepatic failure, gastrointestinal hemorrhage and central nervous system lesions.

Electrocardiographic findings: An electrocardiogram was obtained in 22 patients during the terminal illness. That of only one patient, a neonate, was entirely normal. Thirty-nine distinct electrocardiographic abnormalities were seen in the remaining 21 patients (Table II). $T$ wave abnormalities were the most commonly encountered change and were often dramatic, acute in onset and evolutionary. A major new intraventricular or $\mathrm{A}-\mathrm{V}$ conduction disturbance was seen in 10 patients (excluding the patient with old left bundle branch block), and 5 experienced supraventricular arrhythmias; 3 patients had new QRS changes mimicking myocardial infarction. Despite the dominant left ventricular myocardial involvement with either focal lesions or multiple microabscesses in all patients, only one patient had ventricular premature beats.

Review of chest roentgenograms was not helpful in defining the cardiac problems encountered. Most patients had significant radiographically demonstrable

\section{TABLE II}

Electrocardiographic Findings*

\begin{tabular}{|c|c|c|}
\hline Electrocardiographic Findings & $\begin{array}{c}\text { Group I } \\
\text { (Myocarditis) } \\
\text { (no. = 31) }\end{array}$ & $\begin{array}{c}\text { Group II } \\
\text { (Without } \\
\text { Myo- } \\
\text { carditis) } \\
\text { (no. = 19) }\end{array}$ \\
\hline \multicolumn{3}{|l|}{1 No electrocardiogram available during } \\
\hline 2 Normal & 1 & 4 \\
\hline $3 \mathrm{~T}$ wave abnormalities & 13 & 4 \\
\hline 4 Supraventricular arrhythmia & 5 & $i$ \\
\hline 5 Left bundle branch block & 2 & - \\
\hline $\begin{array}{l}6 \text { Nonspecific intraventricular conduc- } \\
\text { tion delay }\end{array}$ & 2 & - \\
\hline $\begin{array}{l}7 \text { QRS changes (without S-T elevation) } \\
\text { mimicking anterior myocardial }\end{array}$ & & \\
\hline infarction & 3 & -. \\
\hline $81^{\circ} \mathrm{A} \cdot \mathrm{V}$ block & 2 & - \\
\hline 9 Complete A-V block & 1 & - \\
\hline 10 Left anterior fascicular block & $i$ & - \\
\hline $\begin{array}{l}11 \text { Right bundle branch block with left } \\
\text { anterior fascicular block }\end{array}$ & 1 & - \\
\hline 12 Premature ventricular contractions & 1 & - \\
\hline 13 Right bundle branch block & 1 & - \\
\hline
\end{tabular}
ness. The abnormalities are not mutually exclusive. 
pulmonary disease; however, because portable radiographic equipment was frequently used, estimation of heart size and changes in pulmonary vascularity were difficult to assess.

\section{Group II (Cases Without Myocardial Involvement)}

Nineteen patients with systemic candidiasis without myocardial involvement were identified according to the following criteria: positive ante- or post-mortem blood cultures, or microscopic identification of typical organisms located in major organs, excluding the respiratory tract, gastrointestinal tract and urinary bladder. The underlying illness, age of patient at death, and the organism recovered were comparable with findings in Group I (Table 1). 'There were 10 male and 9 female subjects. The mean age at death was 39 years.

Of the available electrocardiograms 40 percent were completely normal, a distinct difference from findings in Group I. Only one major arrhythmia, a transient episode of atrial flutter with variable block, was noted. This occurred 2 weeks before death. No other arrhythmia or major conduction defect occurred in this group. Two of the four patients with minor $T$ wave changes

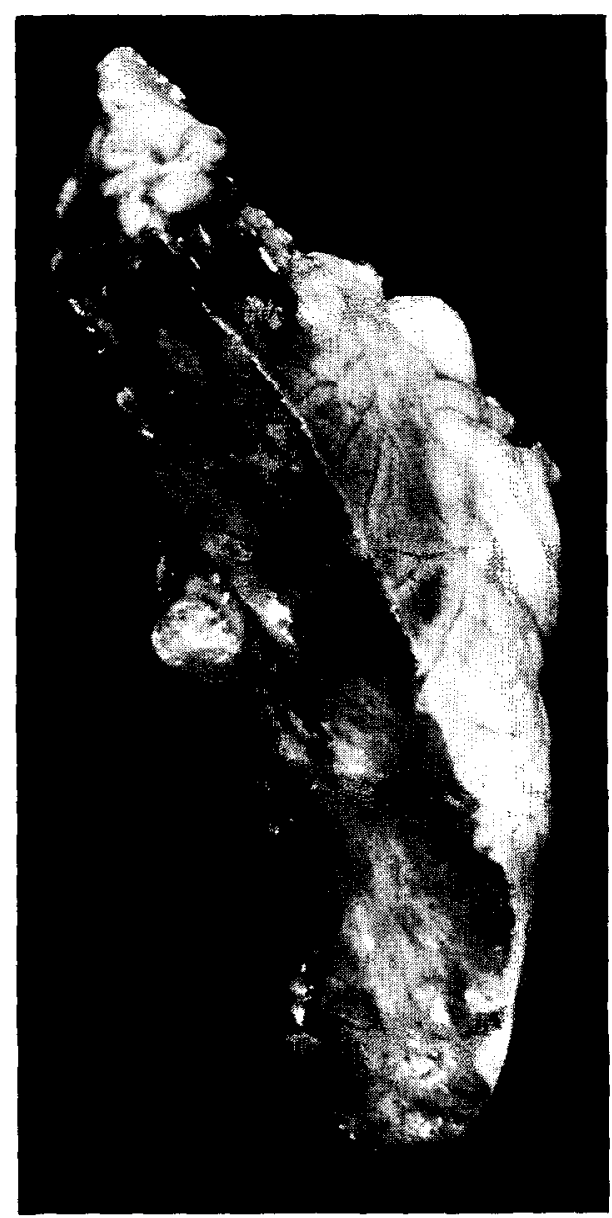

FIGURE 1. Section of left ventricle with multiple gray nodules (arrows) representing Candida myocardial abscesses. were receiving digitalis; no reason could be found for the minor $\mathrm{T}$ wave changes in the other two.

\section{Pathologic Findings}

Necropsy demonstrated myocardial abscesses in all 31 cases of Group I. In only seven were gross lesions evident. These consisted of palpable nodules randomly distributed in either ventricle, although most prominent in the left ventricle (Fig. 1). Depending on the age of the lesion, these consisted of 3 to $15 \mathrm{~mm}$ white to yellow nodules; in two cases a hyperemic border was evident. A fibrinous pericarditis in various stages of organization was present in 10 cases. In five cases, Candida yeast forms were found.

Histologic examination demonstrated microcolonies of yeast cells forming pseudohyphal extensions in radiating patterns, best identified by silver-methenamine or periodic acid-Schiff reaction (Fig. 2). The extent of the inflammatory reaction varied-from complete absence to well developed acute suppuration--depending upon the patient's underlying disease and immune and cell response capabilities (Fig. 3). The microcolonies infiltrated the endomesial interstitial tissue, spreading

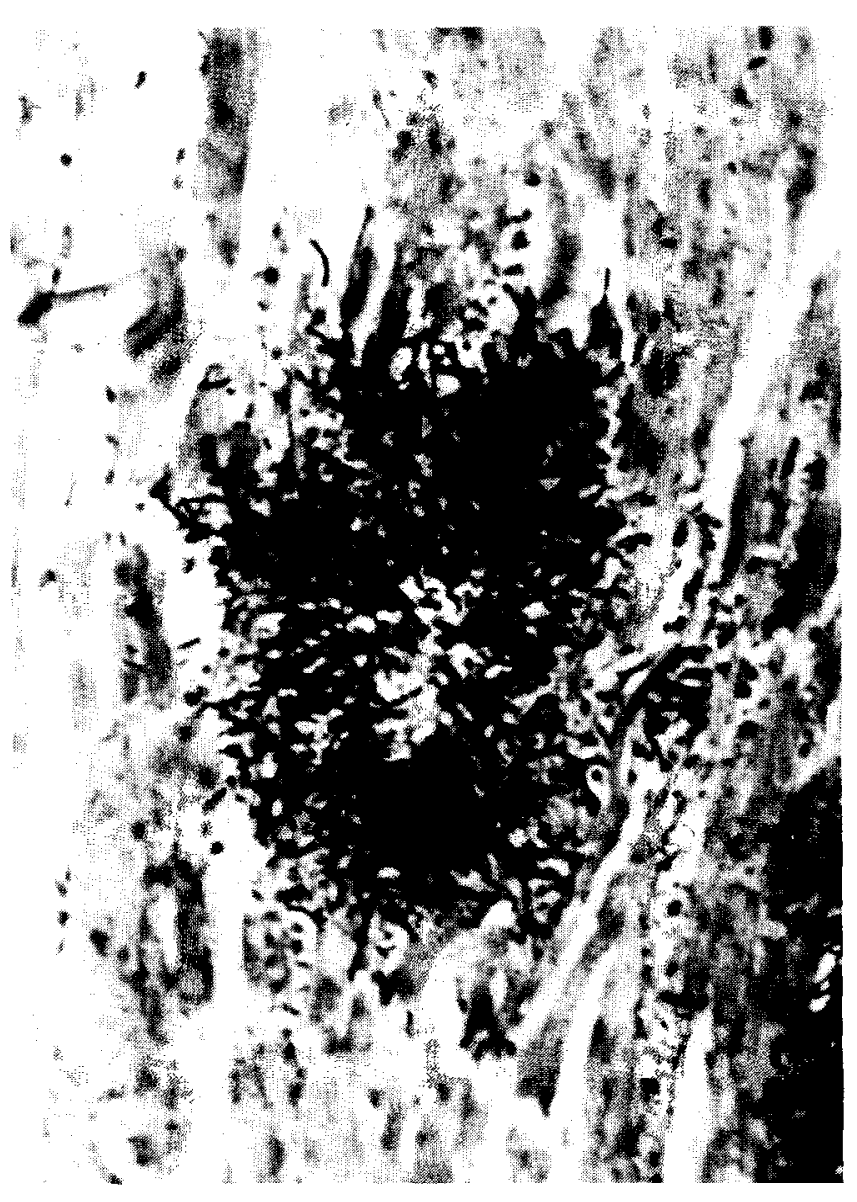

FIGURE 2. Left ventricular myocardium containing a microabscess stained with silver-methenamine to demonstrate pseudohyphal extensions of Candida. (Silver methenamine $\times 285$, reduced by 28 percent.) 
the myocardial fibers. The intervening myocardial fibers exhibited coagulative necrosis; in some cases, depending upon the inflammatory response, central liquification necrosis formed an abscess. Invasion into blood vessels by pseudohyphae occurred, as is commonly found with aspergillus infections (Fig. 4). This invasion could, in turn, cause local thrombosis within the arteriole itself, or result in progression of the inflammatory process by embolization of the organisms to other areas of the myocardium. Inflammation was restricted to the focal lesion and diffuse myocarditis was not found.

The distribution of lesions to the right or left heart chambers was random, as expected with a septicemic origin, with localizations in mural, epicardial and subendocardia! foci. In one case abscesses caused by Candida organisms were found in the conduction system. ${ }^{2}$

In only one case were Candida abscesses restricted to the myocardium and systemic involvement not evident. Focal lesions were present in the kidneys (19 cases), gastrointestinal tract (12 cases), lungs (14 cases), brain ( 6 cases), liver ( 6 cases), and thyroid ( 4 cases). A gas-

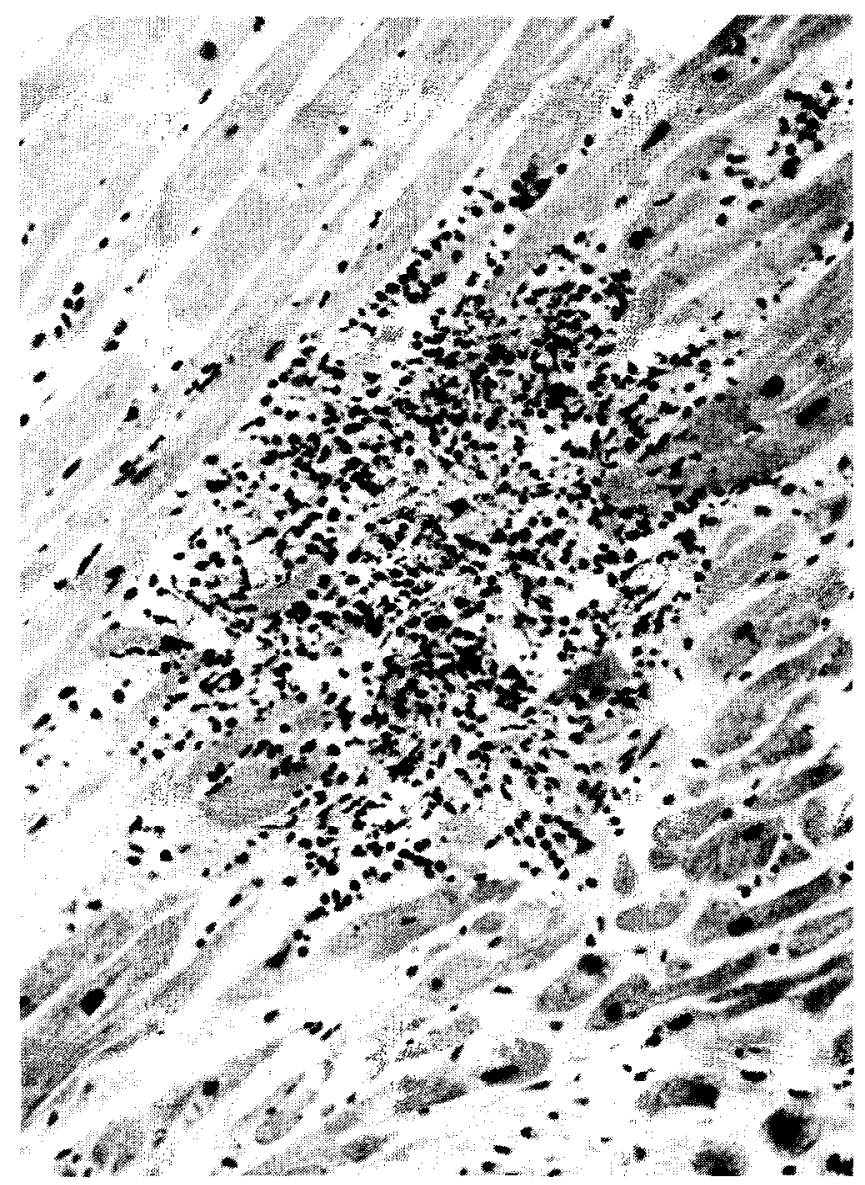

FIGURE 3. Myocardium containing a microabscess. A lymphocytic and plasma cell response to proliferating Candida organisms is evident. Coagulative necrosis of myocardial fibers is present at the margins of the abscess. (Hematoxylin-eosin $\times 120$, reduced by 28 percent.) trointestinal lesion was found in 21 of the 31 cases. Candida forms were found as either mycotic plaques or within ulcerative processes.

In 19 of 24 cases with postmortem blood cultures Candida yeast forms were demonstrated.

\section{Discussion}

Incidence: Candida involvement of the heart is frequently noted at postmortem examination in patients with systemic candidiasis. ${ }^{4-9}$ Of interest is that Candida myocarditis had not been described in the era before the extensive utilization of antibiotic and immunosuppressive agents in clinical practice. ${ }^{3}$ There does not appear to be any doubt that the frequency of Candida infections is increasing, particularly in patients with blood dyscrasias. 4,9

The reported prevalence of cardiac involvement with Candida organisms in patients with systemic candidiasis varies; recent reviews indicate that at least 10 percent $^{7}$ and possibly 63 percent of patients 8 have cardiac involvement. Our data are consistent with the higher figure; 31 of 50 patients ( 62 percent) at our institution with systemic candidiasis had myocardial involvement at postmortem examination. Heretofore, the clinical significance of this involvement was unknown because

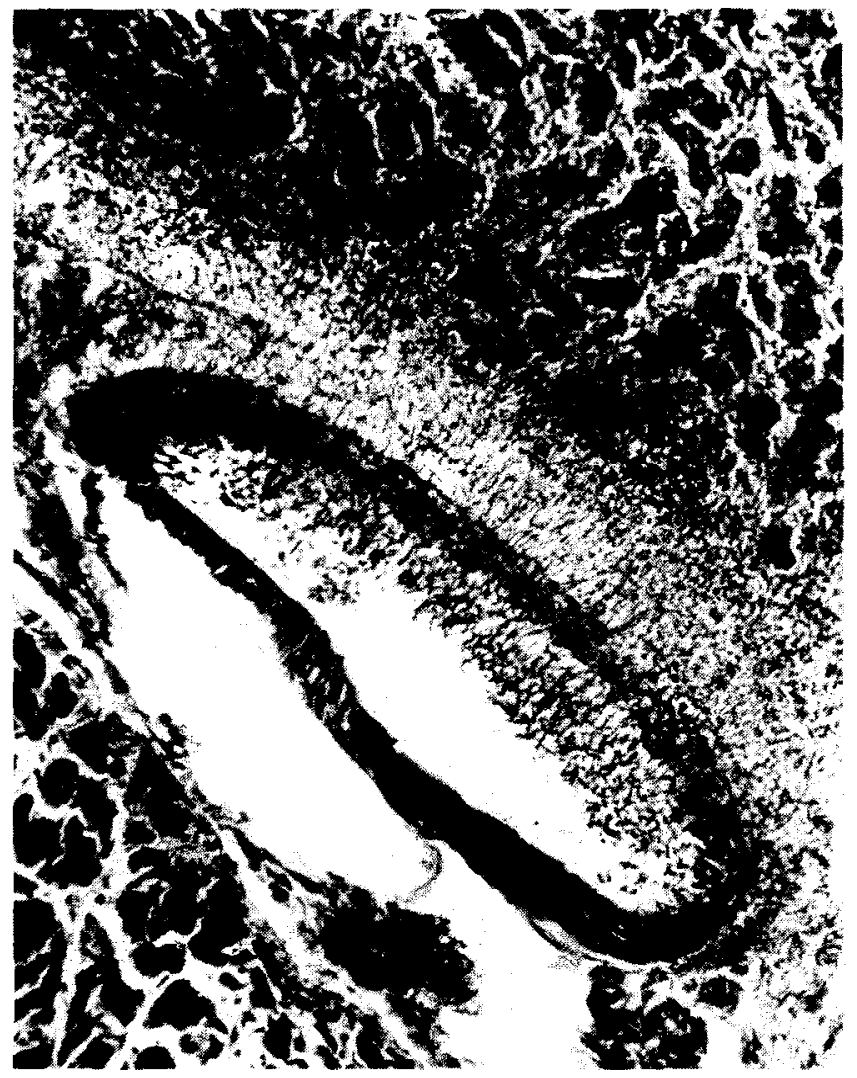

FIGURE 4. Intramural coronary artery with Candida pseudohyphal ingrowth. No inflammatory reaction is present in this patient with immune-suppression. (Hematoxylin-eosin $\times 100$, reduced by 28 percent.) 
there has been no detailed analysis of the clinical course of these patients. Our data indicate that major conduction disturbances and clinically significant arrhythmias result from this involvement.

Cause of hypotension and shock: There are three possible explanations for the hypotension observed in our patients. It may have been due to endotoxic shock from coexistent bacteremia. Septicemia was thought to be present in several patients, but shock often occurred in the absence of gram-negative bacteremia. Although it is possible that hypotension could have resulted from myocardial invasion causing localized or generalized impairment of myocardial contractility, this origin seems unlikely because most patients had small or even only microscopic areas of myocardial involvement. The clinical absence of pulmonary edema also makes this explanation unlikely. It is more likely that hypotension resulted from the release of an endotoxin-like material from the Candida organisms, causing a syndrome pathophysiologically similar to bacteremic endotoxic shock.

Several studies ${ }^{10-12}$ have demonstrated that Candida species possess a material similar to bacterial endotoxin capable of producing clinical findings similar to those of bacteremic endotoxic shock. It would appear that substantially greater quantities of the fungal product than the bacterial product are necessary to produce a similar reaction. ${ }^{12}$

\section{Clinical Implications}

Our patients differ markedly in all respects from those with Candida endocarditis after intracardiac operative procedures. ${ }^{1}$ Only one of our patients had an antecedent cardiac operation. None had new murmurs, gallop sounds, signs of pulmonary edema or embolic phenomena. More than half were immunologically compromised, either by their primary illness or by therapy for it. Nineteen of 31 patients with myocardial involvement were receiving either corticosteroids or antineoplastic agents or both; 27 were receiving one or more antibiotic agents before recovery of the Candida organism.

Although it is not uncommon to recover Candida species from hospitalized patients $(0.8$ percent of all specimens submitted to one bacteriology laboratory ${ }^{1: 3}$ ), systemic candidiasis is implicated in very few cases. The death rate in patients with Candida septicemia with systemic candidiasis approaches 100 percent. In our series, as in others, the patients came from many different services of a general hospital; many had indwelling urinary and intravenous catheters and many had received blood transfusions and had minor or major operative procedures.

The electrocardiographic changes described are in no way specific for Candida myocarditis and are similar to those described by Fine et al. ${ }^{13}$ in a review of electrocardiographic changes in myocarditis of any origin. Their study also demonstrated that fever as such rarely caused even subtle electrocardiographic changes.

Treatment and diagnosis: Only two patients in this series were treated for systemic candidiasis, and one received only $6 \mathrm{mg}$ of Amphotericin B before death. In a third patient the decision to institute therapy was made just before death. The rarity of premortem diagnosis and timely treatment is surprising because 22 patients had positive sputum, blood or wound cultures during their hospital course. The difficulties of selecting treatment for patients with positive cultures for Candida species have been outlined by several authors. ${ }^{1,14,15}$

Myocardial involvement with the Candida organism should be strongly considered when a patient with positive blood, urine or sputum culture for Candida has a major intraventricular or A-V conduction defect, new QRS changes or an arrhythmia. In fact, with only one exception these new electrocardiographic changes were found to be specific for this. New ' $T$ wave changes in the absence of digitalis appear to be a sensitive but less specific indicator of myocardial Candida involvement. Inasmuch as ischemic heart disease, electrolyte disturbances, acid-base disorders and some drugs may produce some of the electrocardiographic changes seen here, the degree of suspicion for Candida myocarditis in the patient with systemic candidiasis should be greatest when electrocardiographic changes are seen in the younger patient without preexistent heart disease or other known causes of the electrocardiographic abnormalities.

\section{References}

1. Seeling MS, Speth CP, Kozinn PF, et al: Patterns of Candida endocarditis following cardiac surgery. Prog Cardiovasc Dis 17: $125-160,1974$

2. Van Kirk JE, Simon AB, Armstrong WR: Candida myocarditis causing complete atrioventricular block. JAMA 227:931-933, 1974

3. Gore I, Sapher O: Myocarditis, a classification of 1402 cases. Am Heart J 34:827-830, 1947

4. Salter W, Zinneman HH: Bacteremia and Candida septicemia. Minn Med 50:1489-1499, 1967

5. Braude Al, Rock JA: The syndrome of acute disseminated moniliasis in adults. Arch Intern Med 104:107-116, 1959

6. Brooks SEH, Young EG: Clinicopathologic observations on systemic moniliasis. Arch Pathol 73:383-389, 1962

7. Gruhn JG, Sanson J: Mycotic infections in leukemic patients at autopsy. Cancer 16:61-63, 1963

8. Louria DB, Stiff DP, Bennett B: Disseminated moniliasis in the adult. Medicine 41:307 333, 1962
9. Hutter RVP, Collins HS: The occurrence of opportunistic fungus infections in a cancer hospital. Lab Invest 11:1035-1045, 1962

10. Salvin SB: Endotoxin in pathologic fungi. J Immun 69:89-99, 1952

11. Braude Al, McConnell J, Douglas H: Fever from pathologic fungi $\mathrm{J}$ Clin Invest 39:1266-1276, 1960

12. Cutler JE, Friedman L, Milner KC: Biological and clinical characterization of toxic substances from Candida albicans. Infect Immun 6:616-627, 1972

13. Fine I, Braunfleld $\mathbf{H}$, Soholow $M$ : Myocarditis in acute infectious diseases. Circulation 2:859-871, 1950

14. Toala P, Schroeder SA, Daly AK, et al: Candida at Boston City Hospital. Clinical and epidemiological characteristics and susceptibility to eight antimicrobial agents. Arch Intern Med 126: 983-989, 1970

15. Ellis CA, Sproack ML: The significance of candidemia. Ann Intern Med 67:511-522, 1967 